\title{
Persistent primitive hypoglossal artery and fenestration of posterior cerebral artery: CT and MR angiography
}

\author{
L. Pasaoglu; H.G. Hatipoglu; M. Vural; I. Ziraman; H.N. Ozcan and S. Koparal
}

Department of Radiology. Ankara Numune Education and Research Hospital. Turkey.

\section{Summary}

Persistent primitive hypoglossal artery (PPHA) which is a persistent carotid-basilar anastomosis is a rare vascular anomaly. It is usually found incidentally. Fenestrations of cerebral arteries are uncommon. Herein we present a case of PPHA with fenestration of posterior cerebral artery. A 28 year old man was admitted to our hospital with complaints of dizziness and temporary loss of vision. Neurological examination revealed no abnormal findings. The patient was further evaluated with $C T$ and MR angiography.

To our knowledge, the case we reported is the first case in the literature with PPHA and fenestration of posterior cerebral artery. The detection of PPHA and associated vascular anomalies and diseases are important before surgical and interventional procedures.

CT and MR angiography are much safer diagnostic alternatives in the detection of PPHA and fenestrations. When PPHA is detected, attention should be given to the coexistent posterior circulation anomalies.

KEY WORDS: Persistent primitive hypoglossal artery. Fenestration. Posterior cerebral artery. CT angiography. MR angiography.

Arteria hipoglosa primitiva persistente y fenestración de la arteria cerebral posterior: hallazgos con TC y angiografía de RM.

\section{Resumen}

La arteria hipoglosa primitiva persistente (AHPP) que es una anastomosis carótido-basilar persistente es una anomalía vascular rara. Se encuentra de forma incidental más frecuentemente. Las fenestraciones de arterias cerebrales son raras. Presentamos aquí un caso de AHPP con fenestración de la arteria cerebral posterior. Un varón de 28 años fue admitido en nuestro

Recibido: 14-09-08. Aceptado: 25-01-09 hospital por presentar mareo y pérdida transitoria de visión. El paciente fue evaluado con TC y angiografía de RM. Para nuestro conocimiento este es el primer caso descrito de una AHPP asociada a fenestración de la arteria cerebral posterior. La detección de AHPP y una anomalía vascular asociada son importantes antes de planificar tratamientos quirúrgicos o endovasculares. EI CT y la angiografía en RM son formas de diagnóstico seguras ante anomalías vasculares. Cuando se detecta una AHPP se debe prestar atención a la coexistencia de anomalías de la circulación posterior.

PALABRAS CLAVE: Arteria hipoglosa primitiva persistente. Fenestración. Arteria cerebral posterior. TC. RM. Angiografía.

\section{Introduction}

Persistent primitive hypoglossal artery (PPHA) is a remnant of the carotid-basilar anastomosis. It normally regresses in the foetus or in the early years of life. PPHA is usually an incidental finding and may be associated with cerebrovascular pathologies like aneurysm, arteriovenous malformation and stenosis ${ }^{6}$. Fenestration of the cerebral arteries are also uncommon ${ }^{4}$. We present a case of PPHA associated with posterior cerebral artery fenestration.

\section{Case Report}

A 28 year old man was admitted to our hospital with complaints of dizziness and temporary loss of vision. Neurological examination revealed no abnormal findings. Computerized tomography (CT) and magnetic resonance imaging (MRI) studies were obtained. CT scan was performed using a 16-detector Toshiba Aquilion system (Toshiba Medical Systems, Otawara, Japan). The imaging and reconstruction parameters were as follows: detector collimation $16 \times 1 \mathrm{~mm}$, voltage $120 \mathrm{kV}$, effective tube current $300 \mathrm{~mA}$, gantry rotation time 420 milliseconds. Image acquisition was performed in inspiratory breathhold. A bolus of $100 \mathrm{ml}$ non-ionic contrast agent (Iome- 

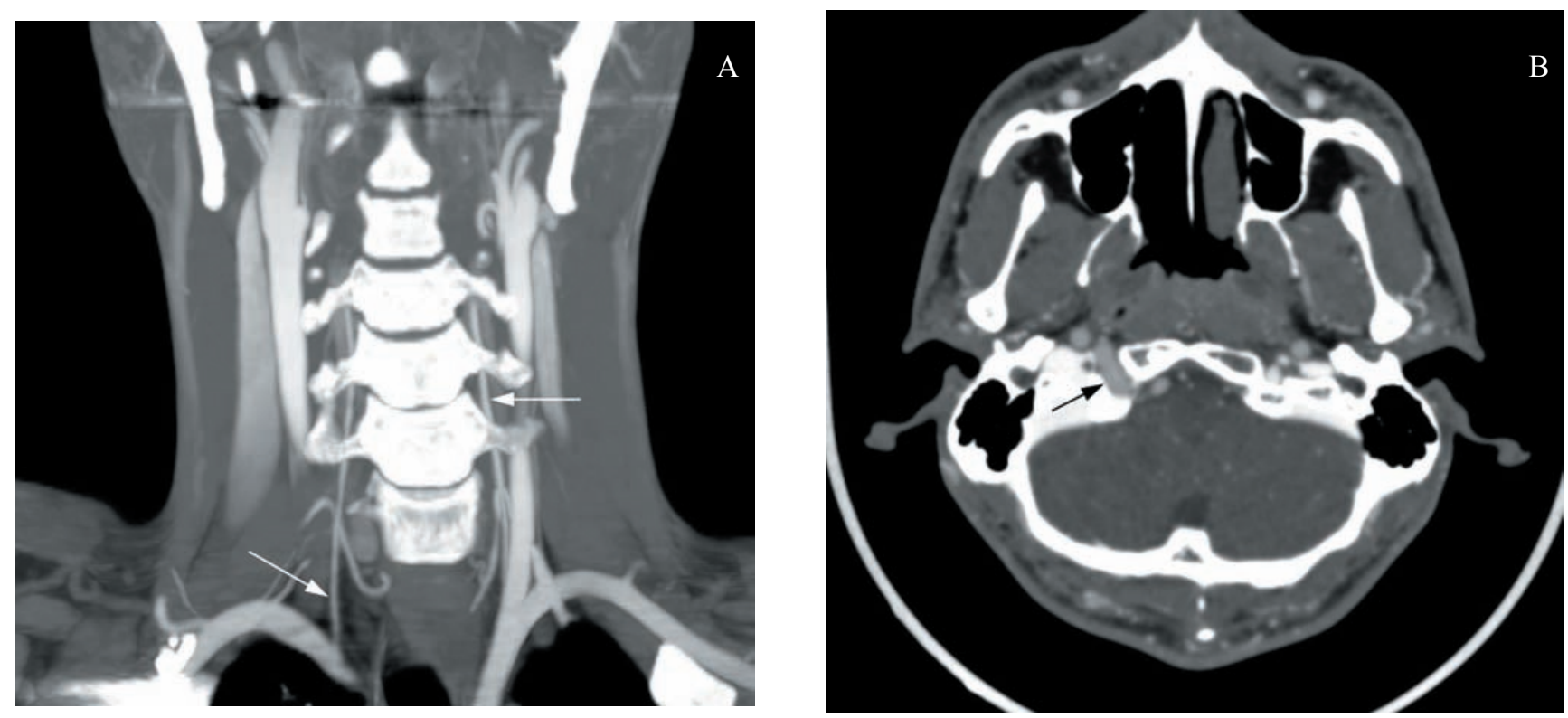

Figure 1. Coronal oblique multiplanar reconstruction CT angiography image demonstrates hypoplastic vertebral arteries (arrows) originating from the subclavian arteries (A). Axial source CT angiography image shows the persistent primitive hypoglossal artery which is joining the lower portion of the basilar artery after passing through the enlarged right hypoglossal canal (arrow) (B).

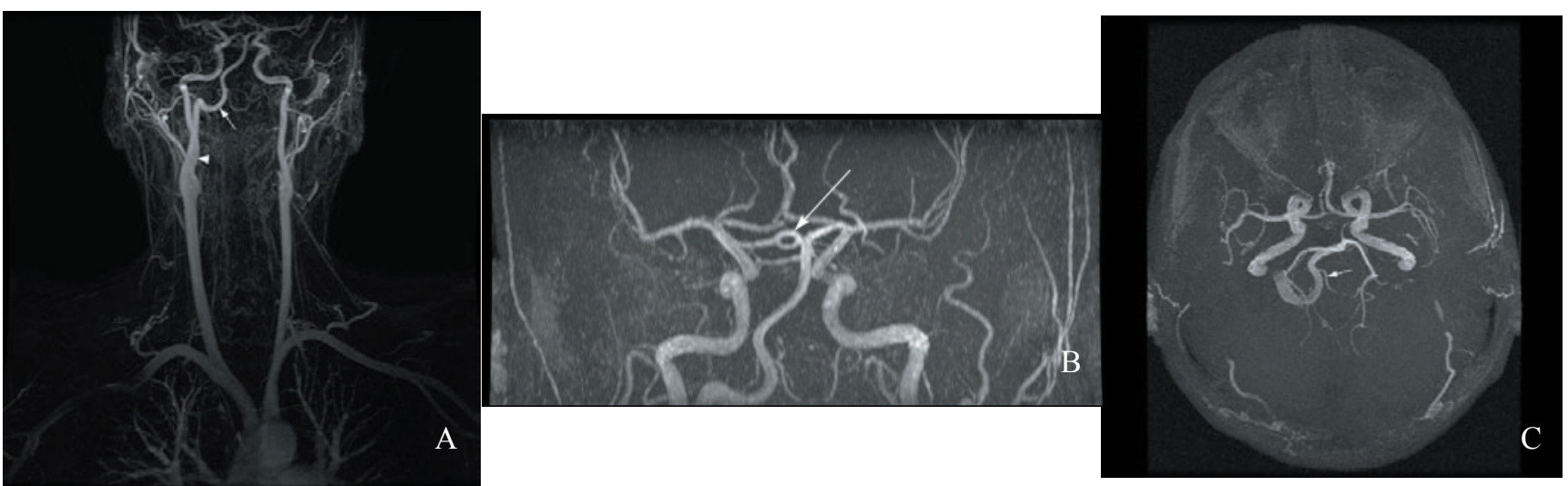

Figure 2. Persistent primitive hypoglossal artery (arrow) originates from the right internal carotid artery (arrowhead) to join the basilar artery (A). Fenestration of the posterior cerebral artery (arrow) is demonstrated (B). The left posterior inferior cerebellar artery (arrow) originates from the persistent primitive hypoglossal artery and the right posterior communicating artery is hypoplastic (C) on multiplanar reconstruction MR angiography images.

prol, Iomeron $350 \mathrm{mgI} / \mathrm{ml}$, Bracco, Italy) was injected in the antebrachial vein with a flow rate of $4.5 \mathrm{ml} / \mathrm{s}$. Data acquisition was initiated by using bolus tracking technique with a threshold value of $120 \mathrm{HU}$. Multiplanar reformats were reconstructed on a Vitrea ${ }^{\circledR}$ post-processing workstation (Vital images, Plymouth, Minnesota). The MRI study was obtained by using unenhanced high resolution three dimensional time-of-flight (TOF) SPGR technique (TR:38 msec, TE: 6 msec, flip angle: 25, band width: 31, NEX:1, Matrix: 320x224, FOV: 20, slice thickness: 1.2, interval:1/ 2 ). A superior saturation band is used. It was performed on a $1.5 \mathrm{~T}$ whole body MRI system (Excite, General Electrics,
Milwaukee, Wisconsin) with a $33 \mathrm{mT} / \mathrm{m}$ maximum gradient capacity. The maximum intensity projection source images were reconstructed on the workstation (Advantage Window). Cranial computed tomography (CT) was normal. CT angiography (CTA) demonstrated two hypoplastic vertebral arteries originating from subclavian arteries which gave terminal cervical branches into the paravertebral musculature above C2 level (Figure 1A). At the C2 vertebra level a large vessel originating from right internal carotid artery was seen, entering the posterior cranial fossa through the hypoglossal canal and joining the lower portion of the basilar artery (Figure 1B). To further analyse vessel 
anatomy magnetic resonance angiography (MRA) was performed. Persistent primitive hypoglossal artery originated from the right internal carotid artery to join the basilar artery (Figure 2A). Fenestration of the posterior cerebral artery was confirmed on both MRA (Figure 2B) and source images of CTA. On MR angiography, the left posterior inferior cerebellar artery (PICA) originating from the right sided PPHA was demonstrated (Figure 2C). There was no right PICA. The right posterior communicating artery was hypoplastic on source images. We didn't obtain a catheter angiography study.

\section{Discussion}

PPHA is one of the four carotid-basilar anastomosis, which exists in the human embryo for 7 days as a temporary communication between the two longitudinal neural arteries and internal carotid artery (ICA). The longitudinal neural artery later becomes the basilar artery ${ }^{6}$. After the posterior communicating arteries developed and vertebral and basilar arteries fused, these temporary collateral vessels gradually disappear. First the otic artery loses its function and the hypoglossal, trigeminal and proatlantal arteries follow it ${ }^{5}$. PPHA is a rare anomaly and estimated incidence is approximately $0.02-0.1 \%{ }^{13}$. PPHA originates as a branch of ICA at the level of C1-C3 vertebrae. After a tortuous course it passes through the enlarged hypoglossal canal and joins the basilar artery. The vertebral arteries are usually hypoplastic or the ipsilateral vertebral artery may be aplastic ${ }^{8}$. In our case, both of the vertebral arteries were hypoplastic. They ended by giving terminal cervical branches to the paravertebral musculature above $\mathrm{C} 2$ vertebra level. The right posterior communicating artery was hypoplastic on the source images of CT and MR angiography. Brismar revised the diagnostic criteria for PPHA in 1976. The two diagnostic criteria of PPHA are as follows: The artery should originate from ICA as an extracranial branch and pass through the hypoglossal canal before joining to the basilar artery ${ }^{1}$. The PPHA is usually found incidentally during routine carotid angiography. However, its identification is clinically important before carotid endarterectomy or skull base surgery. It might be associated with aneurysms, vascular malformations and atherosclerotic diseases ${ }^{3,12,16}$.

Fenestrations of the cerebral arteries are vascular anomalies with a reported incidence as high as $11 \%{ }^{4}$. Anterior communicating artery, vertebrobasilar system and anterior cerebral artery are typical locations for fenestrations ${ }^{14}$. There is one case with ruptured aneurysm from a basilar artery fenestration which was associated with PPHA in the literature 9 . We failed to find any report of posterior cerebral artery fenestration associated with PPHA in the literature and to our knowledge this is the first case with these two cerebral vascular anomalies. The association of fenestra- tion with aneurysms, vascular malformations in case series and herein with PPHA, although the exact relationship isn't defined and needs further assessment, certainly directs us to an embryological or rheological basis for the coexistence. When PPHA is complicated with aneurysm, treatment includes endovascular therapy in addition to clipping or wrapping surgically ${ }^{3}$. The surgical treatment might be risky due to the fact that the posterior circulation is exclusively fed by the PPHA. Endovascular approach can be the treatment of choice for these lesions. When the aneurysm has a wide neck, a stent assisted coil embolization technique could be used ${ }^{2}$.

Most cases of PPHA are diagnosed during catheter angiography. However, with the development of new technologies like CT and MR angiography, diagnosis of PPHA has become easier and safer. Both MR and CT angiography are non-invasive examinations with the advantage of multiplanar demonstration of PPHA by use of 3D reconstruction. In addition to that, MR angiography can demonstrate PPHA without intravenous contrast administration and there is no radiation risk involved. Differentiation between PPHA and proatlantal intersegmental artery may be difficult on angiographic examination because of the similar course of these two primitive arteries 5 . However, CT or MR angiography can easily differentiate these arteries because in contrast to PPHA, the proatlantal intersegmental artery passes through the foramen magnum ${ }^{7}$. 3D CTA can successfully delineate aneurysm and PPHA including the bony structures ${ }^{11}$. In our case, the PPHA and the posterior cerebral artery fenestration were demonstrated accurately with both $\mathrm{CT}$ and MR angiography. Catheter angiography has been considered gold standard in diagnosis of vascular anomalies. It should be considered primarily when peripheral vessels (A3/P3) or internal carotid artery segments close to the skull base (C25) are of interest ${ }^{10}$. 3D CTA may not detect small multiple aneurysms and aneurysms of the posterior communicating artery ${ }^{11}$. Villablanca and colleagues recently described the smallest arterial size reliably detected with multislice CTA as being $0.7 \mathrm{~mm}$ (4-16 slice Scanner) versus $0.4 \mathrm{~mm}$ for $\mathrm{DSA}^{17}$. Although improved spatial resolution has been reported for 3D TOF MRA ${ }^{15}$, CTA and DSA are superior when small vessel disease has to be addressed ${ }^{10}$.

As a conclusion, the detection of PPHA and associated vascular anomalies and diseases are important before surgical or interventional procedures. CT and MR angiography are accurate and much safer diagnostic alternatives. When PPHA is detected, attention should be given to the coexistent posterior circulation anomalies.

\section{References}

1. Agnoli, A.L.: Vascular anomalies and subarachnoid haemorrhage associated with persisting embryonic vessels. Acta 
Neurochir 1982; 60:183-199

2. Baldi, S., Zander, T., Rabellino, M., Maynar, M.: StentAssisted Coil Embolization of a Wide-Neck Aneurysm of a Persistent Primitive Hypoglossal Artery. Cardiovasc Intervent Radiol 2008; Aug 13 (Epub ahead of print).

3. Baltsavias, G.M., Chourmouzi, D., Tasianas, N., Drevelengas, A., Damianovski, D., Jovkovski, S.: Ruptured aneurysm of a persistent primitive hypoglossal artery treated by endovascular approach--case report and literature review. Surg Neurol 2007; 68: 338-343.

4. Bharatha, A., Aviv, R.I., White, J., Fox, A.J., Symons, S.P.: Intracranial arterial fenestrations: frequency on CT angiography and association with other vascular lesions. Surg Radiol Anat 2008; 30: 397-401.

5. Brismar, J.: Persistent hypoglossal artery, diagnostic criteria. Report of a case. Acta Radiol Diagn 1976; 17: 160-166.

6. Elhammady, M.S., Baskaya, M.K., Sonmez, O.F., Morcos, J.J.: Persistent primitive hypoglossal artery with retrograde flow from the vertebrobasilar system: a case report. Neurosurg Rev 2007; 30: 345-349.

7. Fujita, N., Shimada, N., Takimoto, H., Satou, T.: MR appearence of the persistent hypoglossal artery. Am J Neurol AJNR 1995; 16: 990-992.

8. Guerri-Guttenberg, R.A.: Fetal carotid-vertebrobasilar anastomoses: persistent hypoglossal artery associated with further variations of the circle of Willis. Surg Radiol Anat 2008; Sep 2 (Epub ahead of print).

9. Kanematsu, M., Satoh, K., Nakajima, N., Hamazaki, F., Nagahiro, S.: Ruptured aneurysm arising from a basilar artery fenestration and associated with a persistent primitive hypoglossal artery. Case report and review of the literature. J Neurosurg 2004; 101: 532-535.

10. Klingebiel, R., Kentenich, M., Bauknecht, H.C., Masuhr, F., Siebert, E., Busch, M., Bohner, G. Comparative evaluation of 64-slice CT angiography and digital subtraction angiography in assessing the cervicocranial vasculature. Vasc

\section{Comment to the manuscript Persistent primitive hypo- glossal artery and fenestration of posterior cerebral artery: CT and MR angiography by Pasaoglu et al.}

Persistent anastomoses between the carotid and vertebrobasilar systems are not uncommon, Padget and Lasjaunias named these vessels, and their terminology is still used, with the most frequent being the persistent trigeminal artery. More proximal anastomoses via the internal auditory meatus (otic artery) and hypoglossal foramen (hypoglossal artery) are less frequent, as is the persistent proatlantal artery.

These anastomoses most commonly are an incidental finding; however it may be of clinical significance in some
Health Risk Manag 2008; 4: 901-907.

11. Kobayashi, M., Akaji, K., Tanizaki, Y., Mihara, B., Ohira, T., Kawase, T.: Posterior inferior cerebellar artery aneurysm associated with persistent primitive hypoglossal artery. Neurol Med Chir (Tokyo) 2008; 48: 259-261.

12. Kodama, N., Ohara, H., Suzuki, J.: Persistent hypoglossal artery associated with aneurysms. Report of two cases. J Neurosurg 1976; 45: 449-451.

13. Ouriel, K., Green, R,M., DeWeese, J.A.: Anomalous carotid-basilar anastomosis in cerebrovascular surgery. J Vasc Surg 1988; 7: 774-777.

14. Sanders, W.P., Sorek, P.A., Mehta, B.A.: Fenestration of intracranial arteries with special attention to associated aneurysms and other anomalies. Am J Neurol AJNR 1993; 14: 675-680.

15. Schellinger, P.D., Richter, G., Köhrmann, M., Dorfler, A.: Noninvasive angiography (magnetic resonance and computed tomography) in the diagnosis of ischemic cerebrovascular disease. Cerebrovasc Dis 2007; 24 (Suppl 1):1 6-23.

16. Sugiyama, N., Yamashita, N., Kamiya, K., Fukuoka, H., Nagai, H.: Two cases of persistent primitive artery associated with anterior communicating aneurysm. No Shinkei Geka 1987; 15: 1361-1364.

17. Villablanca, J.P., Rodriguez, F.J., Stockman, T., Dahliwal, S., Omura, M., Hazany, S., Sayre, J.: MDCT angiography for detection and quantifi cation of small intracranial arteries: comparison with conventional catheter angiography. AJR Am J Roentgenol 2007; 188: 593-602.

Pasaoglu, L.; Hatipoglu, H.G.; Vural, M.; Ziraman, I.; Ozcan, H.N.; Koparal, S.: Persistent primitive hypoglossal artery and fenestration of posterior cerebral artery: CT and MR angiography. Neurocirugía 2009; 20: 563-566.

Corresponding author: Hatice Gul Hatipoglu. Maresal Fevzi Cakmak cad. 64/A Besevler-Ankara/Turkey.

situations and could be a source of complication for surgery, embolization and other endovascular techniques.

Pasaoglu et al present a case of persistent primitive hypoglossal artery associated with posterior cerebral artery fenestration demonstrated with CT angiography and MR angiography, giving evidence of the increasing importance of these techniques for the presurgical study.

P. Navia Madrid 